\title{
Conexões
}

Educação Fisica, Esporte e Saúde

Artigo Original

\section{A lógica interna das lutas corporais e suas implicações no processo de ensino-aprendizagem nas aulas de Educação Física escolar}

Vagner Augusto de Oliveira Schmidt ${ }^{1}$

Raquel Valente de Oliveira²

\section{RESUMO}

Introdução: Vista somente como um meio de proteção e autodefesa, as lutas passaram a integrar diferentes materiais pedagógicos referentes à Educação Física, tornando-se um dos conteúdos dessa disciplina escolar. Entretanto, seu processo de ensino-aprendizagem ainda é negligenciado. Objetivo: Nessa perspectiva, a presente pesquisa tem como objetivo compreender a lógica interna das Lutas Corporais a partir do Sistema de Classificação CAI e da distância de guarda, apontando suas implicações no processo de ensino-aprendizagem dessas modalidades esportivas. Metodologia: Para isso, foi realizada uma pesquisa bibliográfica, com o intuito de apresentar novas possibilidades que orientem o processo de ensino-aprendizagem das Lutas Corporais, a partir dos conceitos e proposições da Praxiologia Motriz. Resultados: De acordo com o Sistema de Classificação CAI constatou-se que as Lutas Corporais são práticas sociomotrizes de oposição, realizadas em meio físico padrão. Já em relação à distância de guarda, tais modalidades podem ser classificadas como distância quase nula, distância reduzida, distância média e grande distância. Considerações Finais: Por meio da compreensão da lógica interna e da distância de guarda dessas modalidades, o professor poderá orientar e organizar sua prática pedagógica nas aulas de Educação Física.

Palavras-chave: Lutas. Praxiologia motriz. Ensino-aprendizagem. Educação física. Conteúdo escolar.

\footnotetext{
1 Universidade Federal de Santa Maria.

2 Universidade Federal do Rio Grande do Sul.
}

\section{Correspondencia:}

Vagner Augusto de Oliveira Schmidt. Universidade Federal de Santa Maria, Av. Roraima, 1000, Cidade Universitária, Camobi, CEP 97105-900, Santa Maria - RS, Email: vagner.vet@hotmail.com 


\section{The internal logic of body fights and its implications for the teaching-learning process in school Physical Education classes}

\section{ABSTRACT}

Introduction: Viewed only as a means of protection and self-defense, the fights began to integrate all diferent pedagogical materials related to School Physical Education, becoming one content of this scholar discipline. However, their teaching-learning process is still neglected. Objective: In this perspective, the present research aims to understand the internal logic of body fights from the CAI Classification System and the guard distance, pointing out its implications in the teaching-learning process of these modalities. Methodology: For this, was realized a bibliographical research, it was possible to present a possibility to guide the teachinglearning process of the body fights, from Motor Praxeology concepts and propositions. Results: According to the CAI Classification System, it was found that the body fights are opposing sociomotor practices, carried out in a standard physical environment. Regarding the guard distance, these modalities can be classified as almost zero distance, reduced distance, medium distance and great distance. Final Considerations: Through the understanding of the internal logic and distance of guard of these modalities, the teacher can guide and organize his pedagogical practice in Physical Education classes.

Keywords: Fights. Motor praxeology. Teaching-learning. Physical education. School content.

\section{La lógica interna de las luchas corporales y sus implicaciones en el proceso de enseñanza-aprendizaje en las clases de Educación Física de la escuela}

\section{RESUMEN}

Introducción: Visto solo como un medio de protección y defensa personal, las luchas comenzaron a integrar diferentes materiales pedagógicos referentes a la Educación Física, convirtiéndose en uno de los contenidos de esta disciplina escolar. Sin embargo, su proceso de enseñanza-aprendizaje todavía se descuida. Objetivo: En esta perspectiva, la presente investigación tiene como objetivo comprender la lógica interna de las Luchas Corporales del Sistema de Clasificación CAI y la distancia de guardia, señalando sus implicaciones en el proceso de enseñanza-aprendizaje de estas modalidades. Metodologia: Para ello, se realizó una investigación bibliográfica con el fin de presentar nuevas posibilidades que guíen el proceso de enseñanza-aprendizaje de Luchas Corporales, basado en los conceptos y proposiciones del Praxiología Motriz. Resultados: De acuerdo con el Sistema de Clasificación CAI, se descubrió que las Luchas Corporales son prácticas sociomotoras opuestas, realizadas en un entorno físico estándar. En cuanto a la distancia de guardia, estas modalidades se pueden clasificar como distancia casi cero, distancia reducida, distancia media y gran distancia. Consideraciones Finales: Al comprender la lógica interna y la distancia de guardia de estas modalidades, el maestro podrá guiar y organizar su práctica pedagógica en las clases de Educación Física.

Palabras Clave: Luchas. Praxiología motriz. Enseñanza-aprendizaje. Educación física. Contenido escolar. 


\section{INTRODUÇÃO}

Presente na cultura de diferentes sociedades ao longo dos séculos, as lutas são reconhecidas como ritos, práticas religiosas, preparação para a guerra, jogos, exercícios físicos, assim como temática de ensino da Educação Física escolar, entre outros diferentes significados que lhes vêm sendo atribuídos. De acordo com Rufino (2014), as lutas estão relacionadas com os seres humanos desde os períodos mais remotos da existência, como práticas de sobrevivência que foram sendo modificadas por processos históricos, até chegarem às modalidades que se tem nos dias de hoje. Relatos de povos antigos descrevem as distintas manifestações de atividades de lutas que expressavam seus costumes e tradições, delineando sua história, fosse ela ocidental ou oriental (ESPARTERO, 1999).

Segundo Rufino (2014), o termo luta é utilizado em diversos contextos além da prática esportiva, como a luta pela sobrevivência, por um amor, pela terra e entre classes sociais. À mercê desse entendimento, Pucineli (2004) defende que a nomenclatura a ser utilizada para referir-se à Luta como prática corporal é "Lutas Corporais", devido aos vários outros significados que o termo pode agregar. Portanto, nesta pesquisa, serão abordadas as Lutas Corporais provenientes da Cultura Corporal de Movimento que, segundo Amador Ramírez (1994), são jogos finitos realizados entre duas pessoas, de soma zero ${ }^{3}$, cujos interesses são opostos em relação ao resultado.

Quanto às características de sua lógica interna, é possível afirmar que todos os esportes de Lutas apresentam interação de oposição, porém nem todos os esportes de oposição são caracterizados como Lutas, como é o caso do tênis e do badminton individual (AMADOR RAMÍREZ, 1994). A diferença das Lutas em relação a outros esportes de oposição está no espaço/alvo centrado no corpo do adversário, o qual mantém um permanente e intermitente contato corporal, com ou sem instrumento mediador, de acordo com as regras de cada modalidade.

As Lutas Corporais estão frequentemente presentes em nosso cotidiano, em diversas academias, na mídia e no contexto escolar como um dos conteúdos da Educação Física. Entretanto, seu processo de ensino-aprendizagem ainda é marcado por um modelo técnico previamente concebido, com ações motoras estruturadas anteriormente ao vínculo do aluno com a modalidade (FRANCHINI; DEL VECCHIO, 2012). Esse modelo tradicional de ensino prima por práticas pouco reflexivas, com o emprego de técnicas que são demonstradas aos alunos sem incentivar a aprendizagem criativa e consciente, com o ensino de gestos em quantidades elevadas

\footnotetext{
${ }^{3}$ No jogo de soma zero, o benefício total para os jogadores, assim como todas as combinações estratégicas, sempre terá resultado igual a zero. Em outras palavras, para que um lutador possa ganhar a luta, consequentemente o outro deve perder $(1-1=0)$.
} 
de repetições, de forma contraditória às demandas da lógica interna das Lutas Corporais. Esse modelo tradicional estrutura o processo de ensino-aprendizagem sem considerar os elementos que compõem o funcionamento das Lutas Corporais, principalmente no que diz respeito à interação de oposição.

Nesta lacuna é que se destaca a Praxiologia Motriz, proposta pelo professor francês Pierre Parlebas, na qual caracteriza-se como uma ciência que consiste no estudo da ação motriz entendida a partir do contexto da lógica interna das práticas motrizes (PARLEBAS, 2001). Essa teoria possibilita novos critérios para sistematizar e desvelar os conhecimentos da Educação Física, auxiliando o professor em seu trabalho pedagógico, mediante os mais diversos conteúdos que essa disciplina escolar aborda. A partir deste exposto, esta pesquisa tem como objetivo compreender a lógica interna das Lutas Corporais a partir do Sistema de Classificação CAI e da distância de guarda, apontando suas implicações no processo de ensinoaprendizagem dessas modalidades esportivas.

O conceito de lógica interna ganha relevância no contexto brasileiro no momento em que o mais recente documento normativo curricular do país, a Base Nacional Comum Curricular (BNCC), classifica a unidade temática dos Esportes a partir da lógica interna das modalidades (BRASIL, 2018). Essa referência ao conceito de lógica interna apontada pela BNCC (BRASIL, 2018) ressalta a importância do tema proposto por esta pesquisa, bem como de seu desenvolvimento nas aulas de Educação Física escolar, pois compõem, junto com Brincadeiras e Jogos, Esportes, Ginásticas, Danças e Práticas Corporais de Aventura, uma das seis unidades temáticas a serem trabalhadas na escola. Segundo a BNCC, a unidade temática das Lutas engloba "disputas corporais, nas quais os participantes empregam técnicas, táticas e estratégias específicas para imobilizar, desequilibrar, atingir ou excluir o oponente de um determinado espaço, combinando ações de ataque e defesa" (BRASIL, 2018, p. 218).

Além das Lutas representarem o contexto comunitário e regional de uma população, elas também podem retratar o território brasileiro (capoeira, huka-huka, luta marajoara), assim como de diversos países do mundo (judô, aikido, jiu-jítsu, muay thai, boxe, chinese boxing, esgrima, kendo) (BRASIL, 2018). Sabe-se que a temática das Lutas Corporais compreende um material vasto a ser trabalhado, porém ainda restam muitas inquietações a serem respondidas para que o professor se sinta seguro ao organizar essa temática, no sentido de potencializar seu ensinoaprendizagem.

\section{MÉTODO}

Para alcançar os objetivos propostos realizou-se uma pesquisa bibliográfica, ao levantar estudos científicos produzidos acerca do tema de investigação (em 
artigos, livros, dissertações e teses). Para Lakatos e Marconi (2003), a pesquisa bibliográfica proporciona ao pesquisador um contato direto com o que foi escrito, dito ou filmado sobre determinado assunto. Segundo Gil (2008), esse tipo de pesquisa é desenvolvido a partir de materiais já elaborados, constituído principalmente de livros e artigos científicos. Quanto ao nível da pesquisa, o estudo caracteriza-se por ser de cunho exploratório, pois tem como principal objetivo "desenvolver, esclarecer e modificar conceitos e ideias, tendo em vista a formulação de problemas mais precisos ou hipóteses pesquisáveis para estudos posteriores" (GIL, 2008, p. 27).

Para a delimitação do referencial teórico, bem como para a construção dos resultados deste estudo, utilizou-se dos critérios de Salvador (1986): parâmetro temático, principais fontes, parâmetro linguístico e parâmetro cronológico. No que se refere ao parâmetro temático e às principais fontes, foram consideradas produções científicas que discorrem sobre as Lutas Corporais e elementos relacionados ao processo de ensino-aprendizagem, assim como obras acerca da Praxiologia Motriz e alguns de seus conceitos, como o Sistema de Classificação CAI, a distância de guarda, a antecipação motriz, as interações motrizes, a lógica interna e as ações motrizes.

Em relação ao parâmetro linguístico, restringiu-se a pesquisa aos estudos da literatura nacional, devido à facilitação na interpretação dos dados, bem como obras em espanhol, por serem bases teóricas clássicas em relação à Praxiologia Motriz. Já no que tange ao parâmetro cronológico, não foi realizado um recorte temporal do referencial teórico para evitar a exclusão de fontes essenciais para a realização da pesquisa. Além disso, não foi delimitado o número de produções científicas a serem analisadas e utilizadas no estudo, pois isso poderia excluir informações relevantes para sua elaboração.

Em suma, foram empregados estudos que vêm a contemplar as discussões acerca das Lutas Corporais sob as lentes da Praxiologia Motriz, a fim de apresentar suas contribuições para o processo de ensino-aprendizagem. Fundamentado nesse panorama teórico, a pesquisa se sustentou na análise das Lutas Corporais a partir do Sistema de Classificação CAI e da classificação da distância de guarda. Ao salientar a lógica interna das Lutas Corporais, a Praxiologia Motriz contempla a problemática da pesquisa, o que a torna eixo norteador da discussão proposta.

\section{Resultados E Discussão}

A Praxiologia Motriz, idealizada no final da década de 1960 por Pierre Parlebas, é uma ciência que observa as ações motrizes provenientes dos jogos, esportes e demais práticas motrizes que compõem a área da Educação Física, 
buscando extrair conhecimentos que permeiam as diferentes manifestações da Cultura Corporal de Movimento meio da compreensão de sua lógica interna (LAGARDERA; LAVEGA, 2003). Dentre os conceitos advindos da Praxiologia Motriz, tem-se alguns instrumentos de análise, cuja função é desvelar o mundo dos jogos e esportes a partir da compreensão da lógica interna representada pelas ações motrizes. Cada prática motriz dispõe de uma organização própria que comporta certas constantes estruturais. Esta ordem que inclui a lógica interna de qualquer jogo orienta as ações motrizes de seus participantes, que apesar de poderem tomar decisões, devem atuar dentro dos limites de interação da prática motriz (LAGARDERA; LAVEGA, 2003).

O conjunto de preceitos, condições e relações que as regras de jogo estabelecem, recebe a denominação de lógica interna, ou seja, o modo peculiar como as ações do jogo esportivo está pré-determinado (RODRIGUES, 2004). Conforme Lagardera e Lavega (2003), desvelar a lógica interna de cada situação motriz possibilita uma análise prévia do sistema praxiológico, de forma que se possa escolher e programar situações motrizes condizentes aos interesses e propósito dos jogadores. As características da lógica interna estão ligadas diretamente ao sistema de obrigações impostos pelas regras do jogo esportivo. Ribas (2005) reforça que a lógica interna é uma estrutura lógica composta pelo jogo ou esporte, pelos protagonistas, pelos agentes ativos envolvidos e por suas regras, comportando as características importantes da prática motriz.

Através de ferramentas científicas de análise, a lógica interna permite uma maior compreensão sobre as diferentes práticas motrizes. Nesse sentido, Parlebas (1988) elaborou o Sistema de Classificação CAI, no qual se constitui como a primeira abordagem para conhecer o funcionamento de um jogo ou esporte. A partir dos critérios utilizados para organizá-lo, é possível conhecer as principais características de qualquer prática motriz (RIBAS, 2014). Compreender esse modelo de organização permite que o professor de Educação Física tenha condições de intervir diretamente na prática, podendo planejar sua ação de maneira lógica e eficaz (LAGARDERA; LAVEGA, 2003).

A fim de classificar as práticas motrizes conforme as características pertinentes a sua lógica interna, o Sistema de Classificação CAI é estruturado com base nas interações motrizes estabelecidas com companheiros (C), adversários (A) e com a incerteza do meio de prática (I). A combinação desses três critérios (companheiro, adversário e ambiente) possibilita caracterizar qualquer situação motriz, conforme a sistematização disposta abaixo. 


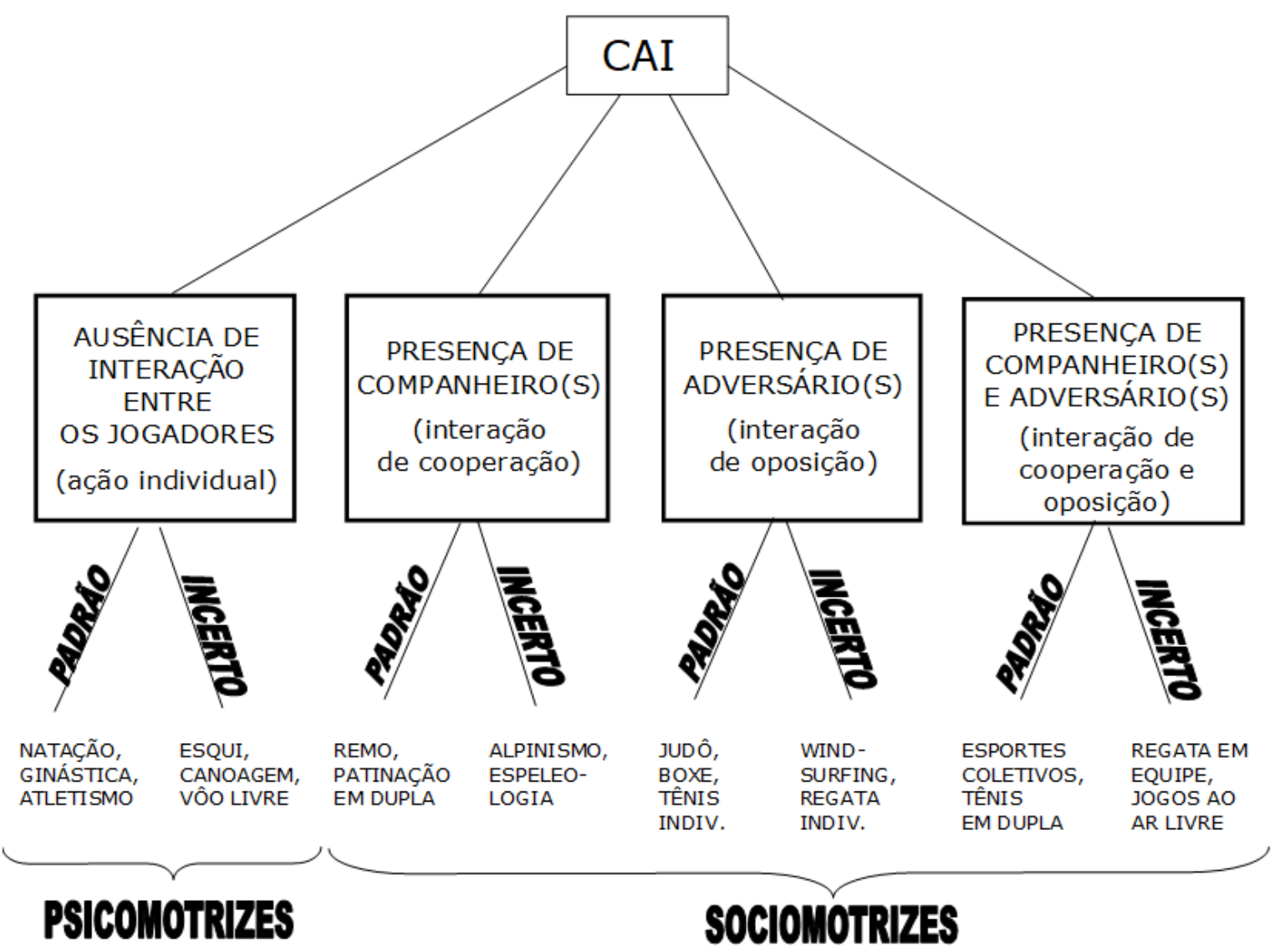

Figura 1 - Sistema de Classificação CAI. Fonte: Adaptada de Parlebas (1987).

Por meio do Sistema de Classificação CAI é possível classificar as modalidades pertencentes às Lutas Corporais como práticas sociomotrizes de oposição (contracomunicação motriz) e com o entorno físico estável (padrão e conhecido pelos praticantes). Compreender as Lutas Corporais como práticas sociomotrizes, ou seja, com interação motriz entre duas pessoas, é essencial para se pensar essa temática, uma vez que essas práticas, em muitas situações, são vistas como esportes individuais. Apesar da responsabilidade sobre a vitória/derrota ser individual, sua prática não acontece sem a interação opositiva de um segundo participante.

Portanto, acredita-se que esse conceito de esporte individual sobre as diferentes modalidades de Lutas Corporais deve ser superado, de modo a orientar seu processo de ensino-aprendizagem a partir da interação motriz de oposição estabelecida entre os jogadores, balizado em sua lógica interna e nos conhecimentos apresentados pelo Sistema de Classificação CAI. Ribas (2014) corrobora com isso ao descrever que, ao classificar o judô como um esporte individual, não se está considerando a essência e as características dessa prática. $\mathrm{O}$ autor ainda questiona se ensinar o aluno a executar golpes individualmente 0 possibilitará empregar tais ações mediante um adversário no momento real e situacional da luta propriamente dita. 
De acordo com o Sistema de Classificação CAI, o judô é uma prática sociomotriz de oposição, ou seja, com interação de contracomunicação. Por conseguinte, mais do que saber empregar golpes, o praticante deve ler o comportamento do adversário à medida em que o combate se desenvolve, para além da realização de movimentos padronizados e descontextualizados da lógica interna do jogo. A partir disso, pode-se questionar os Katis/Katas ${ }^{4}$ como método para o ensino do jogo de Luta, ao desconsiderar a interação motriz de oposição e a necessidade de desenvolver a tomada de decisão dos alunos.

A maioria das Lutas Corporais, sejam elas artes marciais, jogos tradicionais de lutas ou esportes de combate, são orientadas a partir de sua respectiva lógica interna, em que dois indivíduos interagem, essencialmente, por oposição. Tendo em vista a contracomunicação motriz estabelecida entre os jogadores, o lutador deve dificultar as mensagens e informações corporais a seu adversário, de forma que o mesmo não perceba sua real intenção ou golpe que será aplicado. Ao mesmo tempo, o lutador deve interpretar as mensagens do adversário, para que não sofra golpes efetivos, para que consiga a melhor defesa e para preparar seu ataque ou contra-ataque. A maneira como essas mensagens corporais se apresentam depende das possibilidades estabelecidas nas regras de cada uma das modalidades de Lutas Corporais. Tais princípios contracomunicativos inseridos nas práticas das Lutas Corporais devem balizar o processo de ensino-aprendizagem dessas manifestações, em seus diversos contextos de prática.

Para que os processos contracomunicativos e as interações de oposição sejam efetivas nas Lutas Corporais, a leitura realizada pelo lutador durante a execução das ações motrizes deverá sempre considerar a relação opositiva com o adversário para, posteriormente, antecipar-se a ele (RIBAS, 2005). Na maioria dos embates corporais, o lutador tem o mínimo de tempo para perceber/ler o adversário e tomar a melhor decisão em relação ao ataque ou à defesa que deverá executar. É um processo que exige velocidade de reação e contra-ataque e, por essa razão, atividades que privilegiem a interação de oposição são fundamentais durante o processo de ensino-aprendizagem das Lutas Corporais. É através de situações reais de oposição que surge a necessidade de ler/interpretar as ações do adversário e de desenvolver a tomada de decisão do aluno para resolução da situação motriz. O aluno deverá estar em um constante processo de leitura, buscando antecipar-se às possíveis ações do adversário. A antecipação motriz consiste, portanto, em um fator essencial para a organização estratégica do participante em situações com interação de oposição, como no caso das Lutas Corporais.

No que diz respeito às Lutas Corporais, as práticas de oposição são aquelas em que um indivíduo enfrenta o outro e não tem a possibilidade de estabelecer o

\footnotetext{
${ }^{4}$ Os Katis/Katas são formas e demonstrações de Lutas Corporais, com movimentos coreografados e ações previsíveis (RUFINO, 2014).
} 
comportamento cooperativo com qualquer parceiro. Isso destaca sua responsabilidade exclusiva com o resultado e com a realização das ações, sem depender de outro(s) companheiro(s) (AVELAR; FIGUEIREDO, 2009). A partir de estudos da Praxiologia Motriz, Rufino e Darido (2015, p. 46) compreendem as Lutas como "práticas corporais geralmente individuais, com características de enfrentamento direto entre oponentes, os quais são dirigidos por determinadas regras que norteiam ações realizadas em um ambiente". Essa compreensão destaca a característica de oposição existente entre os componentes do sistema praxiológico.

Para Avelar e Figueiredo (2009), as Lutas e os esportes de combate são definidos como modalidades em que um confronto direto é estabelecido entre dois adversários, sendo que o objetivo de ambos é vencer. A forma como a vitória é atingida depende da lógica interna de cada modalidade, baseado nas regras do jogo. No entendimento de Rufino (2014), as características mais elementares relacionadas às Lutas, tais como o enfrentamento direto, as regras, a interação de oposição entre indivíduos, o objetivo centrado no corpo da outra pessoa, as ações de caráter simultâneo e a imprevisibilidade, são fundamentais para seu processo de ensino-aprendizagem. Percebe-se que todas essas características estão diretamente relacionadas à lógica interna das Lutas Corporais, pois referem-se às possibilidades de interação com o adversário, pré-estabelecidas no regulamento oficial de cada uma das modalidades de oposição que integram, em seu conjunto, as Lutas Corporais.

Neste sentido, o alvo ou objetivo centrado no corpo humano é uma das características mais peculiares das Lutas Corporais, as quais as diferenciam das demais práticas. Nos esportes de combate, o espaço/alvo é o corpo do adversário, assim, o combatente é o alvo humano (PARLEBAS, 2001). O homem torna-se o objetivo para o outro homem. É no corpo do adversário que se dirige o "gancho" ou o "direto" do boxe, o "agarre" ou a "queda" da luta livre, a "projeção" e o "estrangulamento" do judô e do jiu-jítsu, e o "toque" da esgrima (PARLEBAS, 2003).

Após as elucidações de determinados conhecimentos da Praxiologia Motriz referentes à lógica interna das Lutas Corporais, torna-se necessário ainda discorrer sobre a distância de guarda, conceito também proposto pela Praxiologia Motriz que auxilia na compreensão acerca do funcionamento dessas modalidades. Parlebas (2001, p. 153), define a distância de guarda como "a distância do enfrentamento motor que separa dois indivíduos num duelo esportivo no momento anterior a ação de ataque de um deles". A distância de guarda está relacionada ao conceito praxiológico da distância do enfrentamento motor. Tida como um dos principais elementos de contracomunicação motriz nessas manifestações corporais, a distância de enfrentamento contribui em grande medida a definir a lógica interna de cada modalidade das Lutas Corporais. Pode-se compreender mais sobre o conceito de distância de guardo na figura abaixo. Constata-se então que a 
distância de guarda pode ser dividida em distância quase nula, distância reduzida, distância média e grande distância.

Distância de Guarda cada vez maior

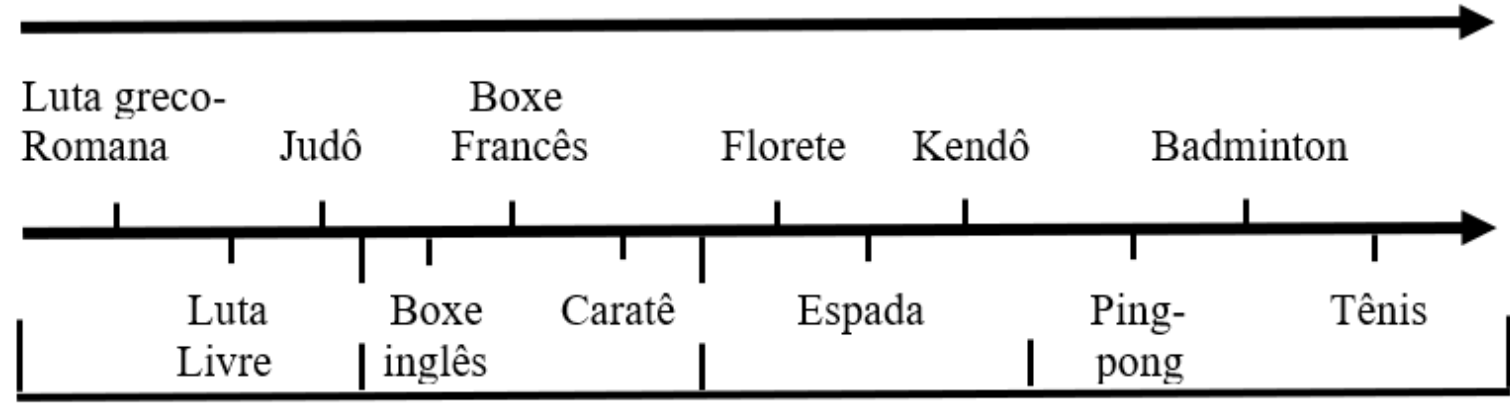

$\begin{array}{cccc}\text { Distância quase nula } & \text { Distância reduzida } & \text { Distância média } & \text { Grande distância } \\ \text { (contato permanente; } & \text { (em espaço próximo; } & \text { (em espaço médio; } & \text { (em espaço longo } \\ \text { a menos de } 1 \mathrm{~m} \text { ) } & \text { de } 1 \text { a } 3 \mathrm{~m}) & \text { de } 3 \text { a } 5 \mathrm{~m} \text { ) } & \text { mais de } 5 \mathrm{~m} \text { ) }\end{array}$

Figura 2 - Classificação Praxiológica da Distância de Guarda.

Fonte: Parlebas (2003, p. 184).

A partir da estruturação de distância de guarda evidenciada na figura acima (figura 2), cabe elucidar os conceitos que definem cada tipo de distância de guarda, pois é de grande relevância para o processo de ensino-aprendizagem das Lutas Corporais. Assim, Parlebas (2003, p. 183-184) descreve que:

Distância quase nula: Menos de um metro. São esportes de combate que necessitam de um contato permanente (luta grecoromana, luta livre, judô). Estes combates sem luvas também autorizam e codificam o combate no solo, um dos objetivos é derrubar o adversário.

Distância reduzida: De um a três metros. Cada pugilista se apresenta próximo ao seu adversário (boxe inglês, boxe francês, Caratê). Os contatos são intermitentes e violentos, os golpes são realizados com os punhos, pés e cotovelos, às vezes com grande impacto. Em comparação com a categoria anterior, em que as técnicas são suaves, esta classe apresenta técnicas mais duras de combate, ambas requerem um imponente gasto energético.

Distância média: De três a cinco metros. Os adversários se enfrentam por mediação de uma "arma" (florete, espada, sabre, bastão), o que determina uma distância de guarda claramente maior. O gasto energético é menor, porém há uma solicitação particularmente aguda de vigilância. As características das armas estão severamente regulamentadas (peso reduzido, ponta romba, fio suprimido e matérias leves) e os combatentes estão protegidos por equipamentos especiais (escudo, máscara, luvas e protetores de pernas).

Grande distância: De mais de cinco metros. Os adversários estão separados por uma distância importante, que no caso do tênis supera os vinte metros. A separação dos protagonistas é total, e o território do praticante é inviolável: uma rede separa o território dos adversários. Neste caso a intermediação é através de uma bola, que 
se golpeia com ajuda de uma raquete. Ao contrário das categorias anteriores, o alvo dos golpes não é o corpo do adversário e sim uma zona do terreno, o que supõe uma diferença fundamental.

Conforme descrito, as distâncias variam de menos de um metro a mais de cinco metros. Nos enfrentamentos de grande distância de guarda, com mais de cinco metros, o objetivo/alvo não está mais centrado no corpo do adversário, o que modifica seu espaço sociomotriz/lógica interna. Porém, Amador Ramírez (1994) elucida que, antigamente, existiam práticas corporais nesta categoria que apresentavam o alvo centrado no corpo do adversário, chamados de "combates a distância com lançamento" (pedras, paus, lanças). Vale destacar que o conceito de distância de guarda diz respeito às práticas de oposição que se caracterizam como duelos individuais de oposição, como é o caso das Lutas Corporais. Conforme Parlebas (2001), nas práticas corporais que apresentam, além da interação de oposição com adversário, interação de cooperação com companheiros, o conceito de distância do enfretamento motor se remete à distância de carga e não à distância de guarda.

Avelar e Figueiredo (2009) afirmam que a distância de guarda afeta o fenômeno das Lutas Corporais, pois a partir dela determina-se o tipo da decisão a ser tomada pelo lutador, cuja abordagem pode promover o que é chamado de "saber lutar". Segundo os autores, o "saber lutar", nesse contexto, representa um recurso que permite ao aluno decidir sobre várias situações que ocorrem durante o combate, independentemente de modelos de execução técnica que caracterizam os diferentes modos e o reconhecimento institucional que impõe certas restrições.

A distância de guarda está diretamente ligada à lógica interna das Lutas Corporais, pois está relacionada às regras e às obrigações, ou seja, ao funcionamento dessas modalidades. A partir disso, as Lutas Corporais assumem certas características, apresentando restrições específicas e distinguindo-se em diversas modalidades, as quais apresentam diferentes papeis sociomotores em cada uma delas. O papel sociomotor é definido como o "conjunto de comportamentos motores que em um jogo esportivo estão associados a um status sociomotor concreto" (PARLEBAS, 2001, p. 399). Baseado nas restrições impostas pelas regras, e considerando a relação com o espaço, instrumento e tempo, o participante imerso em determinada modalidade de Lutas Corporais pode exercer diferentes papeis sociomotores relativos à lógica interna da modalidade em que está lutando.

Apesar de cada modalidade das Lutas Corporais apresentar papeis sociomotores peculiares, é possível identificar algumas ações motrizes comuns entre essas modalidades, dentro de cada subconjunto da classificação praxiológica da distância de guarda. A ação motriz, conceito nuclear da Praxiologia Motriz, expõe essas categorias práxicas em que a ação do jogo é executada (AMADOR RAMÍREZ, 1994). Dessa forma, pode-se identificar diversas ações motrizes comuns entre as muitas modalidades das Lutas Corporais 
presentes em cada um dos grupos previamente classificados pela distância de guarda.

Na distância quase nula, identificam-se as ações motrizes comuns a essa categoria, como: desequilibrar, projetar, controlar, dominar o adversário no solo, chaves e estrangulamentos ou ainda tirá-lo do espaço de jogo (AMADOR RAMÍREZ, 1994). Nessa categoria encontramos várias modalidades de Lutas Corporais presentes no contexto brasileiro, como o Judô, o Brazilian Jiu-Jítsu, o Huka-Huka (luta tradicional indígena) Luta Marajoara (luta tradicional da Ilha de Marajó - PA), Luta Olímpica, Luta Livre, Sumô. Em nenhuma dessas modalidades é permitido algum tipo de "toque percussivo" como socos e chutes, sendo permitido apenas o "agarre".

Na distância reduzida, o golpear com toque é a ação motriz mais presente, a mesma pode ser com os punhos, mãos, antebraços, cotovelos, pés e com os joelhos (AMADOR RAMÍREZ, 1994). A ação motriz pode se apresentar como um golpe efetivo ou com golpes para "marcar" ou "medir" a distância entre os adversários. Nessa categoria, encontra-se o Boxe, o Caratê, o Tae-kwon-do, Kung-fu, Muai-thai.

$\mathrm{Na}$ distância média, tem-se modalidades que utilizam implemento mediador, como espadas ou bastões. A ação motriz essencial que caracteriza esse grupo é o "tocar", podendo o mesmo ser um toque efetivo ou um golpe simulado, somente com a ponta do implemento, ou ainda, com todo o implemento. Já na grande distância de guarda, não se tem atualmente modalidades de Lutas Corporais.

Ao compreender os conceitos de interação de oposição e de distância de guarda, o professor de Educação Física pode organizar e instrumentalizar o processo de ensino-aprendizagem a partir de exercícios, brincadeiras, jogos que apresentem caráter opositivo e das ações motrizes destacadas anteriormente (desequilibrar, projetar, tocar com o próprio corpo ou com implementos, etc.). Isso o possibilita tematizar, ao longo de suas aulas, algumas modalidades, para que o aluno compreenda as semelhanças e as diferenças referentes às Lutas Corporais, a partir da lógica interna e das ações motrizes pertinentes a cada distância de guarda. Ao orientar o processo de ensino-aprendizagem das Lutas Corporais por meio de aspectos relativos à lógica interna e à distância de guarda, o professor estará possibilitando que seu aluno experencie as ações motrizes comuns às diferentes Lutas Corporais, bem como as ações que são específicas de cada uma das modalidades.

Abaixo, o Quadro 1 evidencia as principais ações motrizes provenientes das modalidades das Lutas Corporais, conforme os três tipos de distância de guarda que são aplicáveis a essas práticas motrizes (distância quase nula, distância reduzida e distância média). 
Quadro 1 - Distâncias de Guarda e as Ações Motrizes

\begin{tabular}{|c|c|c|}
\hline \multicolumn{3}{|c|}{ DISTÂNCIA DE GUARDA E AS AÇÕES MOTRIZES } \\
\hline $\begin{array}{c}\text { AČ̃OES MOTRIZES } \\
\text { DISTÂNCIA QUASE NULA }\end{array}$ & $\begin{array}{c}\text { AÇÕES MOTRIZES } \\
\text { DISTÂNCIA REDUZIDA }\end{array}$ & $\begin{array}{l}\text { AÇÕES MOTRIZES } \\
\text { DISTÂNCIA MÉDIA }\end{array}$ \\
\hline $\begin{array}{l}\text { - } \text { DESEQUILIBRAR } \\
\text { - IMOBILIZAR } \\
\text { QUEDAR } \\
\text { - FINALIZAR } \\
\text { EXCLUIR DO ESPAÇO }\end{array}$ & $\begin{array}{l}\text { - GOLPEAR, TOQUE SEM } \\
\text { IMPLEMENTO } \\
\text { MEDIADOR } \\
\text { (Punhos, mãos, } \\
\text { antebraços, cotovelos, } \\
\text { joelhos, pés). }\end{array}$ & $\begin{array}{l}\text { - GOLPEAR, TOQUE COM } \\
\text { IMPLEMENTO } \\
\text { MEDIADOR } \\
\text { (Com a ponta do } \\
\text { implemento ou com } \\
\text { todo implemento). }\end{array}$ \\
\hline
\end{tabular}

Fonte: Adaptado de Amador Ramírez (1994).

Com isso, os conhecimentos praxiológicos ajudam a transcender a ideia de que para aprender algum tipo de Luta Corporal ou esporte de combate é necessário repetir, incessantemente, movimentos exaustivos e desmotivadores. Ribas (2014) destaca que o participante de uma Luta Corporal deve, a todo o momento, ler e interpretar seu adversário e suas ações motrizes, para que assim tenha condições de tomar a melhor decisão e obter sucesso na luta. Nesta perspectiva, as ações motrizes devem ser realizadas em consonância com a interação motriz a qual se remete. Também, devem ser realizadas considerando a lógica de oposição que é estabelecida entre seu adversário e o conceito de antecipação motriz, de modo a superar os métodos de ensino que consideram as Lutas Corporais como esportes individuais. Norteado pelos instrumentos oferecidos pela Praxiologia Motriz, o professor terá condições de apresentar alternativas didáticas que contribuam para a tematização dos conteúdos relacionados as práticas de oposição e, neste caso, especificamente, às Lutas Corporais.

\section{CONSIDERAÇÕES FINAIS}

A partir dos resultados apresentados nesta pesquisa, cujo objetivo foi compreender a lógica interna das Lutas Corporais a partir do Sistema de Classificação CAI e da distância de guarda, torna-se importante ressaltar o quanto a compreensão da lógica interna das Lutas Corporais contribui para a organização do trabalho pedagógico do professor de Educação Física. Ao descrever a lógica interna das Lutas Corporais por meio do Sistema de Classificação CAI, constatouse que esse conjunto de modalidades são classificadas como práticas sociomotrizes de oposição, com o entorno físico padrão e conhecido pelos participantes.

Já em relação à distância de guarda, foram apresentadas suas quatro possibilidades - distância quase nula, distância reduzida, distância média e grande distância, assim como as respectivas ações motrizes por meio das quais os lutadores podem atuar durante o combate. A distância de guarda possibilita ao 
professor organizar as sequências de suas aulas com coerência, sendo, portanto, um referencial na distribuição das diferentes modalidades das Lutas Corporais. 0 professor pode trabalhar a temática das Lutas no decorrer dos anos escolares, balizado na distância de guarda e nas ações motrizes de cada modalidade, instigando os processos de leitura de jogo, antecipação e tomada de decisão em seus alunos.

Os conhecimentos praxiológicos proporcionam um embasamento teórico ao professor de Educação Física, para que este, a partir dos critérios de análise de lógica interna, amplie sua compreensão quanto à estrutura e funcionamento das diferentes práticas motrizes. Ao observar a lógica interna de cada modalidade das Lutas Corporais e o conceito de distância de guarda, o professor pode organizar pedagogicamente os conteúdos conforme a relação apresentada entre eles. Também, pode realizar possíveis transferências de aprendizagem entre as diferentes modalidades das Lutas Corporais, conforme suas semelhanças. Nesse sentido, novos estudos são necessários para aprofundar a temática das Lutas Corporais, considerando a orientação teórica da Praxiologia Motriz.

\section{REFERÊNCIAS}

AMADOR RAMÍREZ, Fernando. Estudio praxiológico de los desportes de lucha. Análisis de la acción de brega en la lucha canaria. 1994. 838 f. Tese (Doutorado em Educação Física)

- Universidad de Las Palmas de Gran Canaria, Las Palmas, 1994.

AVELAR, Bruno; FIGUEIREDO, Abel. La iniciación a los deportes de combate: interpretación de la estrutura del fenómeno lúdico luctatório. Revistas de Artes Marciais Asiáticas, León, v. 4, n. 3, p. 44-57, 2009.

BRASIL. Base Nacional Comum Curricular. Versão final. Brasília: MEC, 2018. Disponível em: http://basenacionalcomum.mec.gov.br/. Acesso em: 18 jul. 2019.

ESPARTERO, Julián. Aproximación histórico-conceptual a los deportes de lucha. In: VILLAMÓN, Miguel. (Org.). Introducción al Judo. Barcelona: Editorial hispano Europea S.A., 1999. p. 23- 54.

FRANCHINI, Emerson; DEL VECCHIO, Fabrício Boscolo. (Orgs.). Ensino de Lutas: reflexões e propostas de programas. São Paulo: Scortecci, 2012.

GIL, Antonio Carlo. Como elaborar projetos de pesquisa. 5. ed. São Paulo: Atlas, 2008.

LAGARDERA, Francisco; LAVEGA, Pere. Introducción a la Praxiología Motriz. Barcelona: Paidotribo, 2003.

LAKATOS, Eva Maria; MARCONi, Marina de Andrade. Fundamentos de metodologia científica. 5. ed. São Paulo: Atlas, 2003.

PARLEBAS, Pierre. Elementos de sociologia del deporte. Málaga: Unisporte, 1988.

PARLEBAS, Pierre. Elementos de sociologia del deporte. Málaga: Unisporte, 2003. 
PARLEBAS, Pierre. Juegos, Deporte Y Sociedad: Léxico de Praxiología Motriz. Barcelona: Paidotribo, 2001.

PARLEBAS, Pierre. Perspectivas para una Educación Física moderna. Málaga: Unisporte, 1987.

PUCINELI, Fabio Augusto. Sobre luta, arte marcial e esporte de combate: diálogos. 2004. 50 f. Monografia (Licenciatura em Educação Física) - Faculdade de Educação Física, Universidade Estadual de Campinas, Campinas, 2004.

RIBAS, João Francisco Magno. (Org.). Praxiologia Motriz e Voleibol: elementos para o trabalho pedagógico. Ijuí: Unijuí, 2014.

RIBAS, João Francisco Magno. Praxiologia Motriz: construção de um novo olhar dos jogos e esportes na escola. Motriz, Rio Claro, v. 11, n. 2, p. 113-120, mai./ago. 2005.

RODRIGUES, Leonel António Ferreira Braz. Praxiologia Motora e efeitos educativos. Lecturas: Educación Física y Deportes, Buenos Aires, v. 10, n. 79, p. 1-1, 2004.

RUFINO, Luiz Gustavo Bonatto. Lutas. In: GONZÁLEZ, Fernando; DARIDO, Suraya; OLIVEIRA, Amauri. (Orgs.). Lutas, capoeiras e práticas corporais de aventura. Maringá: Eduem, 2014. p. 31-67.

RUFINO, Luiz Gustavo Bonatto; DARIDO, Suraya Cristina. O ensino das lutas na escola: possibilidades para a Educação Física. Porto Alegre: Penso, 2015.

SALVADOR, Angelo Domingos. Métodos e técnicas de pesquisa bibliográfica. Porto Alegre: Sulina, 1986. 